\title{
Effect of transcutaneous electrical nerve stimulation on labour pain relief among primigravida and multigravida mothers
}

\author{
Ramamoorthy Veyilmuthu', Sumathi Govindan', \\ Mahalakshmi Venugopalan ${ }^{2 *}$, Seetha Panicker ${ }^{3}$
}

\begin{abstract}
${ }^{1}$ Department of Physical Medicine and Rehabilitation, PSG Hospitals, Coimbatore, Tamil Nadu, India
${ }^{2}$ PSG College of Physiotherapy, Coimbatore, Tamil Nadu, India

${ }^{3}$ Department of Obstetrics and Gynecology, PSG Hospitals, Coimbatore, Tamil Nadu, India
\end{abstract}

Received: 26 December 2016

Accepted: 31 January 2017

\section{*Correspondence:}

Mahalakshmi Venugopalan,

E-mail: mahas_v@yahoo.com

Copyright: (C) the author(s), publisher and licensee Medip Academy. This is an open-access article distributed under the terms of the Creative Commons Attribution Non-Commercial License, which permits unrestricted non-commercial use, distribution, and reproduction in any medium, provided the original work is properly cited.

\begin{abstract}
Background: TENS by neuro-physiological means seems to help in relieving labour pain. Most of the pregnant women are not aware of the coping strategies for labour pain. As a result they tend to be restless and stress themselves by shouting or screaming due to pain. By using TENS, women in labour can save their energy without stressing themselves and make use of the saved energy for pushing the fetus during the second stage of labour. The objective was to analyze the effect of TENS on relieving labour pain among the postnatal mothers who had used TENS to cope up with the labour pain.

Methods: Data collected from 1041 women [Primipara $(n=702)$ and Multipara $(n=339)$ ] who used TENS to cope up pain throughout the labour was used for this retrospective study.

Results: $88 \%$ of women had vaginal delivery and only $12 \%$ of women had cesarean section. More than $50 \%$ of both primiparous and multiparous women who had normal and vacuum assisted vaginal delivery experienced excellent pain relief using TENS. Almost $40 \%$ of both primiparous and multiparous women who had forceps delivery and lower segment cesarean section experienced excellent pain relief using TENS. Except $2 \%$ of women with normal vaginal delivery, none of them stated that there was no relief of pain using TENS.

Conclusions: TENS had a very good effect in coping up the labour pain and could be used during the first and second stages of labour.
\end{abstract}

Keywords: Labour pain, Pain gate theory, TENS

\section{INTRODUCTION}

The pain experienced in labour is affected by the processing of multiple physiological and psychosocial factors. Transcutaneous electrical nerve stimulation (TENS) is widely used for chronic or postoperative pain control, either replacing or complementing analgesic drugs, and is based on the gate theory of pain proposed by Melzack and Wall in 1965. According to this theory, the modulation of pain perception induced by TENS is attributed to the recruitment of A-beta $(A \beta)$ afferent fibers in the posterior horn of the spinal cord, which would prevent or hamper the activation of the painconducting small A-delta (A $\delta$ ) fibers. It is further thought that by reducing anxiety, increasing a sense of control and by providing distraction, TENS increases a woman's sense of well-being and thereby reduces pain in labour (Brucker 1984; Findley 1999; Gentz 2001; Simkin 2004). The first report on the use of TENS in obstetrics came from Scandinavia in the 1970's, where it was introduced as a non-pharmacological resource for pain relief during labor. ${ }^{1}$ TENS by neuro-physiological means seems to help in relieving pain during the first stage of labour. It 
fulfils the criteria of an efficacious, simple to administer method of pain relief with no side effects on the mother and the baby. It would be a useful addition to the present methods of pain relief in labour. ${ }^{2}$

Most of the pregnant women are not aware of the coping strategies for labour pain. As a result, they tend to be restless and stress themselves by shouting or screaming due to pain. It would be better to make them understand about the labour pain beforehand, usually at their final review at obstetrics and gynecology (OG) outpatient department (OPD) and also teach them the method of operating the obstetric TENS equipment to cope up with the labour pain. This would help the women in labour to save their energy without stressing themselves and make use of the saved energy for pushing the fetus during the second stage of labour.

There was no evidence from previous studies with larger sample size and usage of TENS throughout the first and second stage of labour. Hence, this study was conducted with an objective to analyse the effect of TENS on relieving labour pain among the postnatal mothers who had used TENS to cope up with the labour pain during their first and second stages of labour.

\section{METHODS}

\section{Design and sample size}

This is a retrospective study and the data collected from both the primipara and multipara mothers who had used TENS for coping up labour pain throughout labour was used for this study. Ethical clearance was obtained from Institutional Human Ethical Committee, PSG Institute of Medical Sciences and Research, Coimbatore, Tamil Nadu, India. Out of 2595 women who delivered between February 2015 and February 2016, the data of 1041 women [Primipara $(n=702)$ and Multipara $(n=39)$ ] were taken for this study.

The data of 1554 women could not be included, 3 women had assisted breech delivery, 2 women underwent vaginal birth after cesarean (VBAC), 403 underwent elective cesarean, 10 women had twin gestation, 142 women had already had an experience of using TENS for previous delivery, 95 women had immediate progression of labour and 309 women were not willing to use TENS to cope up labour pain.

The data of all the participants showed that they had undergone the awareness programme on the coping strategies of labour pain and about the method of application of TENS equipment when they had visited OG OPD during their final review. The data was then segregated into normal vaginal delivery (NVD), forceps delivery (FD), vacuum assisted vaginal delivery (VAVD) and lower segment cesarean section (LSCS). The feedback forms on relief of labour pain which were collected from the mothers on the first post natal day were used for data analysis.

\section{Intervention}

ELLE Obstetrics TENS equipment had been used for this study. The technique of TENS application involved placement of two pairs of flat electrodes on both side of the woman's thoracic and sacral spines (T10-L1 during the first stage of labour) and (S1-S4 during second stage of labour) as pain is felt at the dermatomal distribution $\mathrm{T} 10$ and $\mathrm{Ll}$.

During full dilation and stretching of the birth canal, pudendal nerve is stimulated at S2-S4 level. These electrodes provided continuous, low-intensity electrical impulses or stimuli from ELLE TENS (battery- operated) device. The pulse frequency used was between $16 \mathrm{~Hz}$ and $100 \mathrm{~Hz}$ with pulse duration of $150 \mu \mathrm{s}$. Two modes are available on the ELLE TENS, each with a burst and boost function (Table 1).

Mode 1 is primarily used for the earlier stages of labour. Mode 2 is used when the labour advanced and when the contractions became more frequent. The burst function button is used in between contractions which promotes secretion of endorphins and encephalins. The boost function button was used during contractions. This gives an extra surge of power required to combat the pain during contractions. The labour ward therapist fixed the electrodes and the women operated the device themselves. The labour ward therapist ensured the proper use of the device and the position of the electrodes frequently.

Table 1: ELLE TENS technical specifications.

\begin{tabular}{|llll|} 
& Pulse frequency $(\mathrm{Hz})$ & Pulse width $(\boldsymbol{H s})$ & Description \\
\hline Burst 1 & 16 & $150^{*}$ & 1 burst/second, 8 pulses / burst \\
\hline Burst 2 & 32 & $150^{*}$ & 2 bursts/second, 8 pulses/burst \\
\hline Boost 1 & 80 & $150^{*}$ & Continuous \\
\hline Boost 2 & 100 & $150^{*}$ & Continuous \\
\hline
\end{tabular}

* Default pulse width after mode changed (pulse width is NOT changed when switched between BURST and BOOST mode). 


\section{Outcome measures and statistical analysis}

The pain index and degree of pain relief were used as outcome measures. The percentage of pain relief was assessed both by the postnatal women and by the therapist (Table 2 and 3). Pain index was calculated by multiplying the pain relief scores assessed both by the postnatal women and therapist. The degree of pain relief was graded accordingly by the therapist in-charge of the obstetrics and gynecological physiotherapy (Table 4).

Table 2: Scores according to percentage of relief by the participant.

\begin{tabular}{|ll|}
\hline Percentage of pain relief & Score \\
\hline $0-25 \%$ & 1 \\
\hline $26-50 \%$ & 2 \\
\hline $51-75 \%$ & 3 \\
\hline $76-100 \%$ & 4 \\
\hline
\end{tabular}

Table 3: Scores according to percentage of relief by the therapist.

\begin{tabular}{|lll|}
\hline Description & $\begin{array}{l}\text { Percentage } \\
\text { of pain relief }\end{array}$ & Score \\
\hline $\begin{array}{l}\text { Moaning or shouting during } \\
\text { contraction }\end{array}$ & $0-25 \%$ & 1 \\
\hline Wincing during contraction & $26-50 \%$ & 2 \\
\hline Restless with discomfort & $51-75 \%$ & 3 \\
\hline Comfortable and sleeping & $76-100 \%$ & 4 \\
\hline
\end{tabular}

Table 4: The pain index and degree of pain relief.

\begin{tabular}{|ll|}
\hline Pain index & Degree of pain relief \\
\hline $1-4$ & No relief \\
\hline $5-8$ & Fair relief \\
\hline $9-12$ & Good relief \\
\hline $13-16$ & Excellent relief \\
\hline
\end{tabular}

\section{Subjective assessment of labour pain (by the postnatal women)}

This variable was standardized by visual analog scale. The distance marked were calculated as a percentage of line length (from 0-100\%). Scores were given according to the percentage of pain relief.

\section{Observer assessment of labour pain (by the therapist)}

This grading of percentage of pain relief and scoring was done by the labour ward therapist who attended the pregnant women during labour.

\section{RESULTS}

Among the 1041 pregnant women who had used TENS for coping up labour pain, it was found that only $12 \%$ of women underwent cesarean section and $88 \%$ of women had vaginal delivery (NVD, FD and VAVD), out of which $58 \%$ were primigravida women. The average duration of application of TENS for the primiparous women was $6.19 \pm 0.46$ hours (Mean and SD) and for that of the multiparous women was $6.09 \pm 1.26$ hours (Mean and SD).

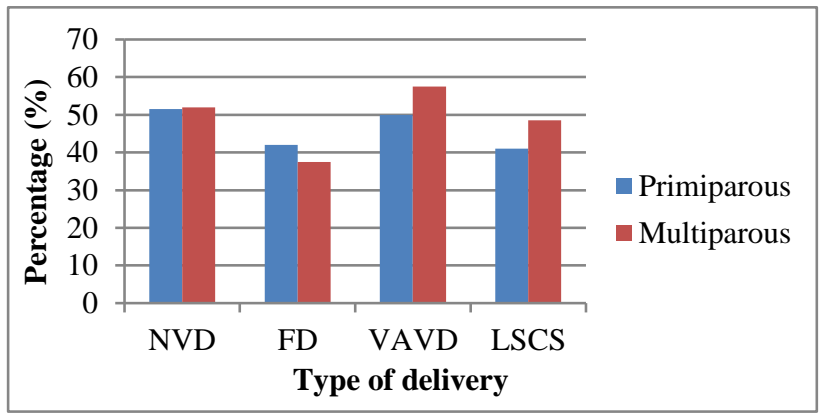

Figure 1: Percentage of pregnant women experienced excellent relief of labour pain using TENS.

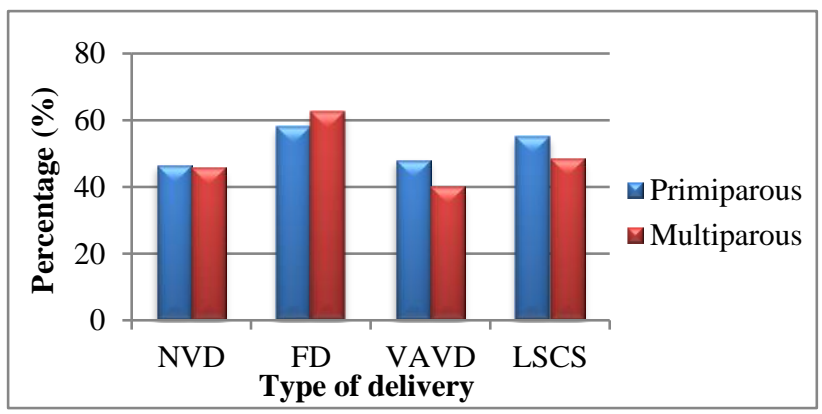

Figure 2: Percentage of pregnant women experienced good relief of labour pain using TENS.

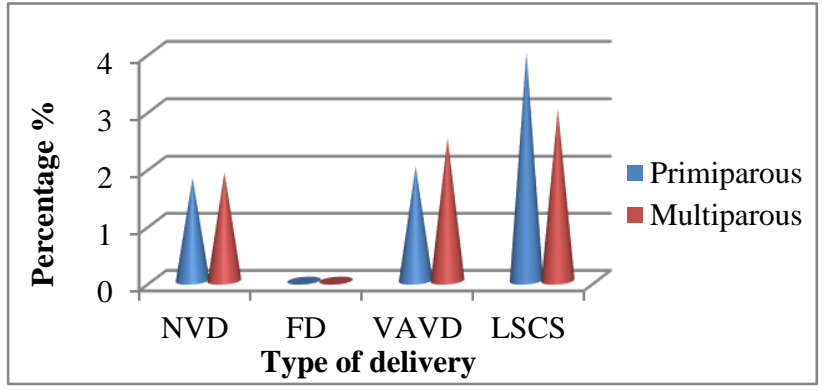

Figure 3: Percentage of pregnant women experienced fair relief of labour pain using TENS.

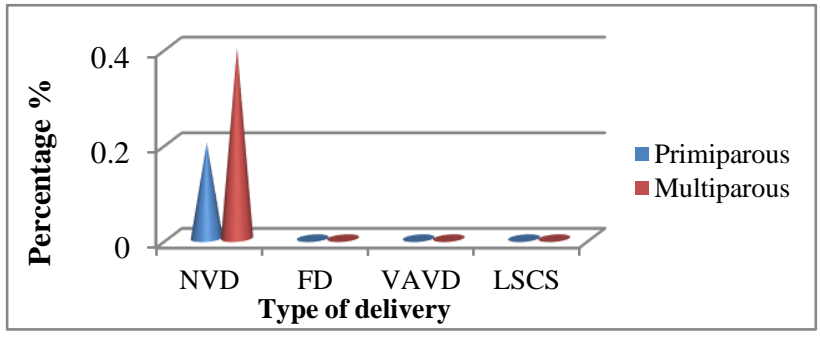

Figure 4: Percentage of pregnant women experienced no relief of labour pain using TENS. 
Table 5: Baseline characteristics of the participants.

\begin{tabular}{|llllllll|}
$\begin{array}{l}\text { Type of } \\
\text { Delivery }\end{array}$ & $\begin{array}{l}\text { No. of } \\
\text { participants } \\
(\%)\end{array}$ & $\begin{array}{l}\text { No. of } \\
\text { primipara (\%) }\end{array}$ & $\begin{array}{l}\text { No. of } \\
\text { multipara (\%) }\end{array}$ & $\begin{array}{r}\text { Primipara } \\
\text { Mean (SD) }\end{array}$ & Multipara & $\begin{array}{l}\text { Primipara } \\
\text { (hours), Mean (SD) }\end{array}$ & Multipara \\
\hline NVD & $740(71 \%)$ & $482(65 \%)$ & $258(35 \%)$ & $24.76 \pm 3.32$ & $26.88 \pm 3.89$ & $6.09 \pm 4.86$ & $5.29 \pm 4.40$ \\
\hline FD & $27(3 \%)$ & $19(70 \%)$ & $8(30 \%)$ & $24.15 \pm 2.26$ & $27.62 \pm 2.66$ & $6.01 \pm 3.95$ & $4.74 \pm 2.54$ \\
\hline VAVD & $144(14 \%)$ & $104(72)$ & $40(28 \%)$ & $25.10 \pm 3.37$ & $27.1 \pm 3.78$ & $5.79 \pm 4.52$ & $7.21 \pm 6.03$ \\
\hline LSCS & $130(12 \%)$ & $97(75 \%)$ & $33(25 \%)$ & $25.82 \pm 3.94$ & $27.42 \pm 4.86$ & $6.85 \pm 5.46$ & $7.10 \pm 5.21$ \\
\hline
\end{tabular}

NVD: Normal vaginal delivery; FD: Forceps delivery; VAVD: Vacuum assisted vaginal delivery; LSCS: Lower segment cesarean section.

\section{Normal vaginal delivery}

It was analyzed from the data that, 740 mothers had normal vaginal delivery. Among them, 482 were primiparous $(24.76 \pm 3.32$ years $)$ and $258(26.88 \pm 3.89$ years) were mulitparous. More than $50 \%$ of both primiparous and multiparous women $(51.5 \%$ and $52 \%$ respectively) experienced excellent pain relief using TENS (Figure 1) and more than $45 \%$ of both primiparous and multiparous women (46.5\% and $45.7 \%$ respectively) had good pain relief (Figure 2). Fair relief and no relief of pain by using TENS have been stated by less than $2 \%$ of the NVD mothers (Figure 3 and 4).

\section{Forceps delivery}

Only twenty seven mothers had forceps delivery. Among the 19 primiparous (24.15 \pm 2.26 years) and 8 multiparous (27.62 \pm 2.66 years) women who had FD, $42 \%$ of the primiparous women and $37.5 \%$ of multiparous women experienced excellent pain relief using TENS (Figure 1). More than $55 \%$ of both primiparous and multiparous women experienced good pain relief by using TENS (Figure 2). None of them have stated that they had fair relief or no relief after using TENS (Figure 3 and 4).

\section{Vacuum assisted vaginal delivery}

One hundred and forty four mothers [primiparous $(\mathrm{n}=104 ; 25.10 \pm 3.37$ years $)$ and multiparous $(\mathrm{n}=40$; $27.1 \pm 3.78$ years)] had VAVD. 52\% of primiparous and $55 \%$ of multiparous women had excellent pain relief (Figure 1). $48 \%$ of primiparous and $40 \%$ of multiparous women experienced good relief (Figure 2). Less than $3 \%$ of them had stated fair relief and none of the VAVD mothers had stated that they had no relief of pain by using TENS to cope up labour pain (Figure 3 and 4).

\section{Lower segment caesarean section}

One hundred and thirty mothers had lower segment cesarean section. Among them 97 mothers were primiparous (25.82 \pm 3.94 years) and 33 were multiparous ( $27.42 \pm 4.86$ years). $41 \%$ of primiparous and $48.5 \%$ of multiparous mothers experienced excellent relief (Figure
1). $55 \%$ of primiparous and $48.5 \%$ of multiparous women experienced good relief of pain (Figure 2). Less than 4\% of them experienced fair relief of pain by using TENS. None of the LSCS participants had stated that there was no pain relief using TENS for coping up labour pain (Figure 3 and 4). These results are summarised in Table 5.

\section{DISCUSSION}

The present study evaluated the relief of pain by the mothers who had used TENS for labour. It was observed in this study that $50.3 \%$ of the mothers had experienced excellent pain relief and $47.4 \%$ of the mothers had experienced good pain relief by using TENS. The knowledge about effectiveness of TENS for labour pain given to the antenatal women during their last review had provided confidence among the women to use the TENS equipment during labour. This correlated with a study which had stated that by reducing anxiety, increasing a sense of control and by providing distraction, TENS increases a woman's sense of well-being and thereby reduces pain in labour. ${ }^{3}$ A study included 14 randomized controlled trials comparing women receiving TENS during labour versus routine care or placebo devices. The authors demonstrated little difference in satisfaction with pain relief or in pain ratings between the TENS and control groups. However, approximately two-thirds of women who had received TENS reported that they would prefer to use it again for future labour and one another study states that $74 \%$ of the parturient in their experimental group reported being satisfied with TENS, and $100 \%$ of them would prefer to use this method again for future childbirths. ${ }^{4,5}$

The findings of the present study are similar to the previous studies with respect to the mode of delivery for the women who had used TENS during labour. In present study about $88 \%$ had vaginal delivery (including NVD, FD and VAVD) and $12 \%$ had emergency caesarean. Thomas et al reported that in their intervention group, $80.3 \%$ vaginal births, $8.3 \%$ forceps/vacuum and $11.4 \%$ caesarean sections. Normal delivery occurred in all women in TENS groups in comparison to $98 \%$ in tramadol group and $99 \%$ in control group. ${ }^{6}$ Use of TENS 
was associated with the shortest first and second stages of labour, and highest rate of spontaneous delivery. ${ }^{7}$

The pulse frequency of the ELLE TENS device which was used in this study ranged between $16 \mathrm{~Hz}$ and $100 \mathrm{~Hz}$ with pulse duration of $150 \mu \mathrm{s}$. The parameters used in present study were similar to the few other related studies, Fayis F El-shamy and Anees G Saleh have applied TENS (Medsana, China) on acupuncture points for 30 minutes, at a frequency of $100 \mathrm{~Hz}$ with a burst frequency of $2 \mathrm{~Hz}$, pulse width $150 \mu \mathrm{s}$, and intensity according to patients tolerance. ${ }^{5,8}$ They have stated that different opioid peptides have been released in central nervous system by TENS application. Encephalins and $\beta$ endorphins are released with TENS application of $2 \mathrm{~Hz}$, while dynorphin is released in the spinal cord with 100$\mathrm{Hz}$, a combination of both frequencies allows synergistic interaction among the three endogenous opioid peptides and provides a powerful analgesic effect. Santana et al, had applied TENS continuously for 30 minutes starting at the beginning of the active phase of labour $(4 \mathrm{~cm}$ of cervical dilation). ${ }^{5}$ The TENS unit produced a modified biphasic asymmetric pulse and was set to a pulse width of $100 \mathrm{~ms}$ and a frequency of $100 \mathrm{~Hz}$.

Elle TENS machine has been used in our study. Lai Fong $\mathrm{HO}$ et al have used the same machine and have stated that we can encourage the labouring women to mobilise even when they are using the TENS machine, which will help in shortening the latent or first stage of labour. ${ }^{7}$ Moreover, it also reduces the incidence of neonatal respiratory suppression caused by pethidine.

In present study, the mean duration of application of TENS for the NVD was $6.09 \pm 4.86$ hours [(Mean and $\mathrm{SD})$; primiparous] and 5.29 \pm 4.40 hours [(Mean and SD); multiparous]. Most of the studies have used TENS for the early stage of labour for 30 minutes. ${ }^{5,8}$ Experienced practitioners state that TENS may be more effective if initiated in early labour, presumably to allow for a buildup in endorphin production before the pain becomes severe. ${ }^{9}$ TENS provides continuous, low-intensity electrical impulses or stimuli and during the contractions the woman increases the stimulation from low to high intensity by turning the control knobs on the device. High intensity should be maintained for at least 1 minute to facilitate release of endorphins. ${ }^{10}$ Similarly one another study has stated that during labour, low-intensity electrical stimulation is given continuously or is applied by the woman herself as the contraction begins. This stimulation blocks the afferent fibers, preventing pain from traveling to the spinal cord synapses from the uterus. As labour and descent progresses, the electrodes are moved to stimulate the S2 and S4 level. High intensity stimulation is generally needed to control the pain at this stage. ${ }^{11}$ In present study, the TENS was given continuously during labour with the women operating the machine, switching to boost and burst modes during contractions and in between contractions respectively. The electrodes were applied at the level of T10-L1 during first stage of labour and S2-S4 during second stage of labour. Duration of application of TENS for the primipara women was comparatively more than that of the multipara women who had ND and FD with a mean difference of 0.8 and 1.27 hours respectively. The current study evaluated the perception of labour pain of 1041 pregnant women and analyzed the effect of TENS to cope up labour pain. This study has strong evidence to state that usage of TENS had good effect in reducing the labour pain for both primigravida and multigravida women.

\section{Limitation}

The intensity of pain depends upon several factors. The most important being the emotional stability of the women. ${ }^{8}$ It also depends upon the pain threshold of women. As it is a retrospective study, the pain threshold of the individual woman could not be identified. Correlation of pain threshold and pain index could be included in future studies. Lack of control group is another limitation of this study. Comparing the women using TENS for labour pain with the women who had sedation could yield good evidence for the effect of TENS for labour pain. Further high quality randomized controlled trials could be done to support the evidence of usage of TENS for labour pain.

\section{CONCLUSION}

It is concluded that TENS had a very good effect in coping up the labour pain and could be used during the first and second stage of labour by both the primigravida and multigravida women. The awareness of labour pain and usage of TENS for labour pain forms the important concept in the childbirth education programme.

\section{ACKNOWLEDGEMENTS}

The authors kindly acknowledge and thank Dr. N. Lalitha, Department of Obstetrics and Gynecology, PSG IMS \& $\mathrm{R}$ Hospitals for reviewing this paper and for providing her valuable suggestions.

\section{Funding: No funding sources}

Conflict of interest: None declared

Ethical approval: The study was approved by the Institutional Ethics Committee of PSG Institute of Medical Sciences and Research, Coimbatore, Tamil Nadu, India

\section{REFERENCES}

1. Mello LFD, Nobrega LF, Lemos A. Transcutaneous electrical stimulation for pain relief during labor: a systematic review and meta-analysis. Rev Bras Fisioter. 2011;15(3);175-84.

2. Padma, Prasanna A, Urala. Transcutaneous electrical nerve stimulation and labour pain. Bahrain Med Bull 2000;22(1):1-8. 
3. Jones L, Othman M, Dowswell T, Alfirevic Z, Gates $\mathrm{S}$, Newburn M, et al. Pain management for women in labour: an overview of systematic reviews. Cochrane Database of Systematic Reviews. 2012;3:CD009234.

4. Bedwell C, Dowswell T, Neilson JP, Lavender T. The use of transcutaneous electrical nerve stimulation (TENS) for pain relief in labour: a review of the evidence. Midwifery. 2011;27(5):e149-8.

5. Santana LS, Gallo RBS, Ferreira CHJ, Duarte G, Quintana SM, Marcolin AC. Transcutaneous electrical nerve stimulation (TENS) reduces pain and postpones the need for pharmacological analgesia during labour: a randomised trial. J Physiotherapy. 2016;62:29-34.

6. Thakur R, Patidar R. Comparative study of transcutaneous electrical nerve stimulation (TENS) and tramadol hydrochloride for pain relief in labor. J Obstet Gynecol Ind. 2004;54(4):346-50.

7. Ho LF, Lee ILY, Gy Ma G, "Intrapartum transcutaneous electrical nerve stimulation for pain relief and outcome of labour", Hong Kong J Gynaecol Obstet Midwifery. 2011;11:54-8.

8. El-shamy FF, Saleh AG. Effect of electroacupoint in treatment of pain during first stage of labour. J Adv Biol. 2014;4(1):328-32.

9. Simkin P, Bolding A. Update on nonpharmacologic approaches to relieve labor pain and prevent suffering. J Midwifery Wom Health. 2004;49(6).

10. Alden KR, Lowdermilk DL, Cashion MC, Perry SE. Maternity and women's health care. 10th Ed. Elsevier Health Sciences: 2013.

11. Pillitteri A. Maternal and child health nursing: care of the childbearing and childrearing family. Lippincott Williams and Wilkins: 2013.

Cite this article as: Ramamoorthy V, Sumathi G, Mahalakshmi V, Seetha P. Effect of transcutaneous electrical nerve stimulation on labour pain relief among primigravida and multigravida mothers. Int $\mathbf{J}$ Reprod Contracept Obstet Gynecol 2017;6:980-5. 